Article

\title{
Average Luminance Calculation in Street Lighting Design, Comparison between BS-EN 13201 and RP-08 Standards
}

\author{
Alexandru Viorel Rusu ${ }^{1, *}$, Catalin Daniel Galatanu ${ }^{2, *(\mathbb{D})}$, Gheorghe Livint ${ }^{1}$ (D) and Dorin Dumitru Lucache ${ }^{1}$ (D) \\ 1 Faculty of Electrical Engineering, Technical University Gheorghe Asachi, 700050 Iasi, Romania; \\ glivint@tuiasi.ro (G.L.); dorin.lucache@tuiasi.ro (D.D.L.) \\ 2 Faculty of Civil Engineering and Building Services, Technical University Gheorghe Asachi, \\ 700050 Iasi, Romania \\ * Correspondence: alexandru-viorel.rusu@student.tuiasi.ro (A.V.R.); catalin.galatanu@tuiasi.ro (C.D.G.); \\ Tel.: +40-755-276-820 (A.V.R.); +40-744-762-941 (C.D.G.)
}

check for

updates

Citation: Rusu, A.V.; Galatanu, C.D.;

Livint, G.; Lucache, D.D. Average

Luminance Calculation in Street

Lighting Design, Comparison

between BS-EN 13201 and RP-08

Standards. Sustainability 2021, 13,

10143. https://doi.org/10.3390/

su131810143

Academic Editors: Pramod Bhusal and Laurent Canale

Received: 29 July 2021

Accepted: 30 August 2021

Published: 10 September 2021

Publisher's Note: MDPI stays neutral with regard to jurisdictional claims in published maps and institutional affiliations.

Copyright: (c) 2021 by the authors. Licensee MDPI, Basel, Switzerland. This article is an open access article distributed under the terms and conditions of the Creative Commons Attribution (CC BY) license (https:/ / creativecommons.org/licenses/by/ $4.0 /)$.

\begin{abstract}
This paper presents a study on the influence of the observer's position in relation to the calculation surface. This is the initial observation of the research, respectively that the two standards consider the position of the observer differently. For these situations, two types of calculations were performed. For the first set of calculations, the software used was DIALux 4.13 as this software can perform calculations in line with the RP-08 standard. The second set of calculations was performed with a script that offers the possibility to change the observer's position. The conclusion was that EN-13201 has a better approach, but both standards could be improved. The second case study refers to the influence of the longitudinal observer position in an average luminance calculation. If one considers RP-08 as a guideline for performing the calculations, the conclusions are that changing the distance from the observer to the calculation surface has absolutely no effect on the average luminance value. On the other hand, if European standards are used as a guideline, changing the distance (from the standardized $60 \mathrm{~m}$, either closer to the calculation surface or further away) can influence the overall results in average luminance and uniformity. Taking into account the results of these two case studies, the conclusion is that both RP-08 and BS-EN 13201 should be updated so that the observer's distance in relation to the calculation surface would be a variable dependent on the stopping distance calculated based on the speed limit of the road.
\end{abstract}

Keywords: average luminance; lighting class; asphalt reflection; observer; uniformity

\section{Introduction}

Street lighting represents one of the main consumers of electricity in the world [1]. It is of great interest to research and consider any means of reducing power consumption, either by making equipment more efficient or by improving the design as much as possible. As [2] demonstrates, even the same standard [3], when updated [4], can have significant differences. Changes can occur, not only for the lighting classes themselves, but when it comes to choosing the lighting classes, which, as other papers demonstrate, can considerably influence energy consumption [5]. IoT systems are more and more accessible and LED lighting has become very popular worldwide, thanks to its efficiency and high life expectancy in comparison to sodium lamps [6]. Considering this, the concept of smart city and individual lamp control has become a reality in most developed countries. Some parts of the world have already restricted companies to selling only high energy efficient light sources, as they are no longer allowed to promote mercury, incandescent or even high-pressure sodium equipment that does not meet energy efficiency requirements $[7,8]$. It is essential that there is a unitary thinking of the standards; therefore, all research is directed toward energy efficiency. For this, standards have already incorporated some energy performance indicators [9] and paper [10] even suggests a classification of road lighting energy efficiency. 
This paper is a continuation of the research presented in a previous paper [5], in which there are several case studies that define all the important lighting classes and determine how much some of the standards [4,11-14] influence the overall power consumption in street lighting installation.

The most important standards analyzed in the studies are the European standards 13201 [4,11,15], which have an important role in the harmonization of street lighting standards across the entire continent. Most of the countries have already taken this as a reference in order to update their own. Another very important standard is the American IES (Illuminating Engineering Society) RP-08 [12], which is already considered not only in most American countries, but also in some countries in Middle East and other areas of the globe. After analyzing the results presented in paper [5], the conclusion was that further research needed to be conducted, since similar average luminance values required higher linear power for the installation $(\mathrm{W} / \mathrm{km}$ ) according to the RP-08 method of calculation, as opposed to the 13201 standards. The theory is that the average luminance value is calculated differently based on the two standards.

The scope of the paper is to investigate the differences in calculating the luminance value between the two standards and to evaluate the variation in the average luminance.

After a detailed comparison, we observed that the main difference between the two standards is the observer positioning, which, as other papers suggest [16], can have a significant influence on the average luminance value due to the reflection properties of the asphalt [17-19]. Considering this, the second section of the paper presents an overview of the differences from the two standards and a case study, for three particular roads in which the average luminance values are compared when calculated with the same input data, but as per the two standards.

The third section presents how the average luminance changes for different longitudinal observer positioning, while section four is a case study in order to support the idea that street lighting design should be customized based on the speed of the road by adjusting the observer position to the braking distance needed.

\section{Observer Positioning in Road Lighting Calculation}

The main parameters in any road lighting calculation are the average luminance and uniformity.

In both standards, luminance at a point is calculated exactly the same way.

$$
\mathrm{L}=\sum_{\mathrm{k}=1}^{\mathrm{n}_{\mathrm{LU}}} \frac{\mathrm{I}_{\mathrm{k}}(\mathrm{C}, \gamma) \times \mathrm{f}_{\mathrm{M}} \times \mathrm{r}_{\mathrm{k}}(\tan \varepsilon, \beta)}{\mathrm{H}_{\mathrm{k}}^{2}}
$$

where

- $\quad \mathrm{L}$ is the maintained luminance in candelas per square meter;

- $\mathrm{k}$ is the index of current luminaire in the summation;

- $\mathrm{n}_{\mathrm{LU}}$ is the number of luminaires involved in the calculation;

- $\quad \mathrm{I}_{\mathrm{k}}(\mathrm{C}, \gamma)$ is the luminous intensity incident in the calculation point from the k-th luminaire, in candela;

- $\quad \mathrm{f}_{\mathrm{M}}$ is the overall maintenance factor, considering the light source lumen maintenance factor and luminaire maintenance factor;

- $\mathrm{r}_{\mathrm{k}}(\tan \varepsilon, \beta)$ is the reduced luminance coefficient for the current incident light path with angular coordinates $\left(\varepsilon_{\mathrm{k}}, \beta_{\mathrm{k}}\right)$;

- $\mathrm{H}_{\mathrm{k}}$ is the mounting height of the $\mathrm{k}$-th luminaire above the surface of the road, in meters.

Even if the luminance at a point is calculated identically for both standards, after performing a set of calculations, the conclusion was that in some cases there can be significant differences in the average luminance even if the input data is identical.

The first step in determining why these differences appear was to analyze each parameter from Equation (1). Considering that the luminaire and arrangement used were 
identical, it is clear that the only parameter that could be different is the reduced luminance coefficient. The R3 tables from the two standards are exactly the same; therefore, the only possible differences are actually the angles based on which the coefficient is interpolated.

Based on Figure 1, the conclusion is that the $\varepsilon$ angles cannot be different if the height and distance to the luminaire are identical, which means that the only parameter that can differ between the two standards is $\beta$.

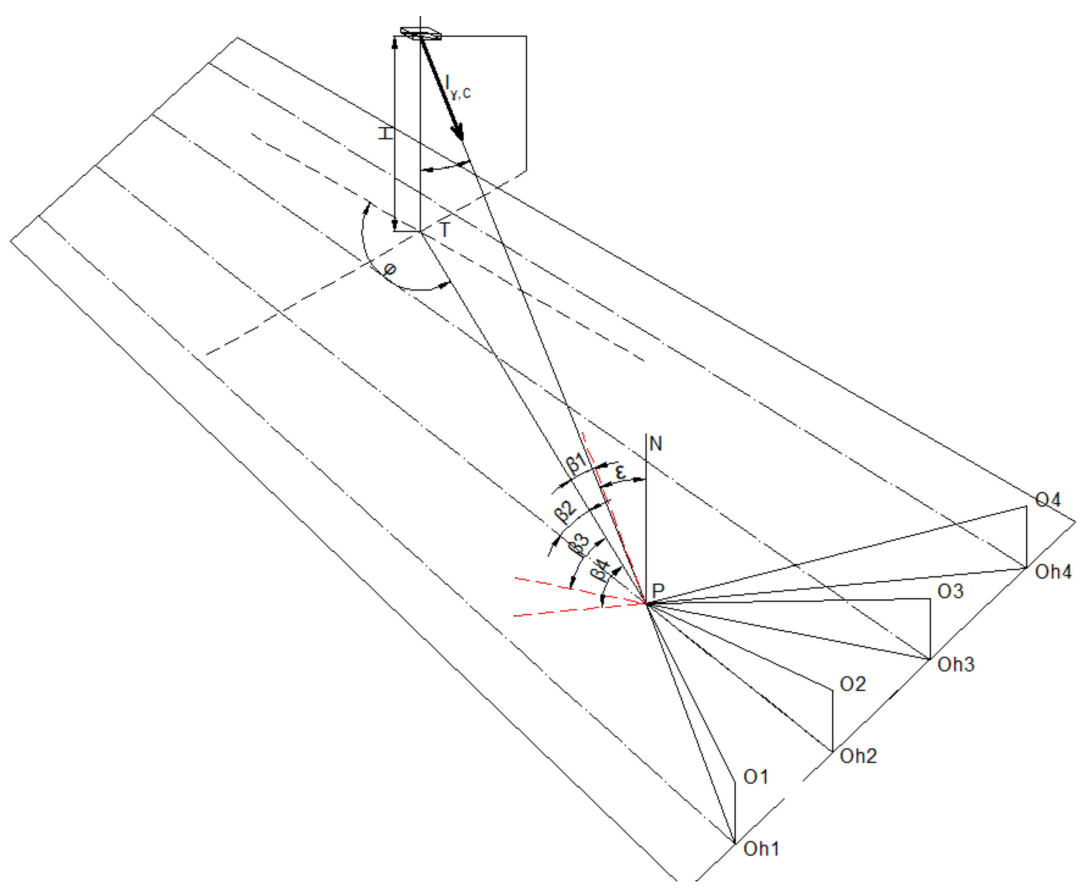

Figure 1. Angular relationships for reduced luminance coefficient, considering luminaires at tilt during measurement, observer and point of observation.

Considering this information, the authors concluded that the difference between the two standards is actually the observer's position for which the calculations are performed.

In [11], it is stated that, "In the transverse direction the observer shall be positioned in the center of each lane in turn. Average luminance, overall uniformity of luminance and threshold increment shall be calculated for the entire carriageway for each position of the observer. Longitudinal uniformity of luminance shall be calculated for each centerline. The operative values of average luminance, overall uniformity of luminance, and longitudinal uniformity of luminance shall be the lowest in each case; the operative value of threshold increment shall be the highest value".

Unlike in [11], the American standard [12] states: "The observer is located on a line parallel to the centerline of the roadway that passes through the calculation point. The observer is located at a distance of $83.07 \mathrm{~m}$ from that point. The eye height of the observer is $1.45 \mathrm{~m}^{\prime \prime}$.

The case-study presents several DIALux calculations performed for a two-lanes, a four-lanes and a six-lanes road, with all types of arrangements in order to see how the results differ if the calculations are performed considering the conditions from the two standards. In all the calculations, the asphalt type selected is R3, imposing exactly the same road surface reflection factor defined in both standards. For all the calculations, the poles will be considered to have a height of $10 \mathrm{~m}$, with no bracket arm. The tilt angles for which the calculations were performed are $0^{\circ}, 10^{\circ}$ and $20^{\circ}$.

In order to have a clear evaluation of how the values are changing, the calculations are performed for the following three types of arrangements: opposite, staggered and single sided.

Figure 2 presents the geometry of the road for the two lanes opposite arrangement. 


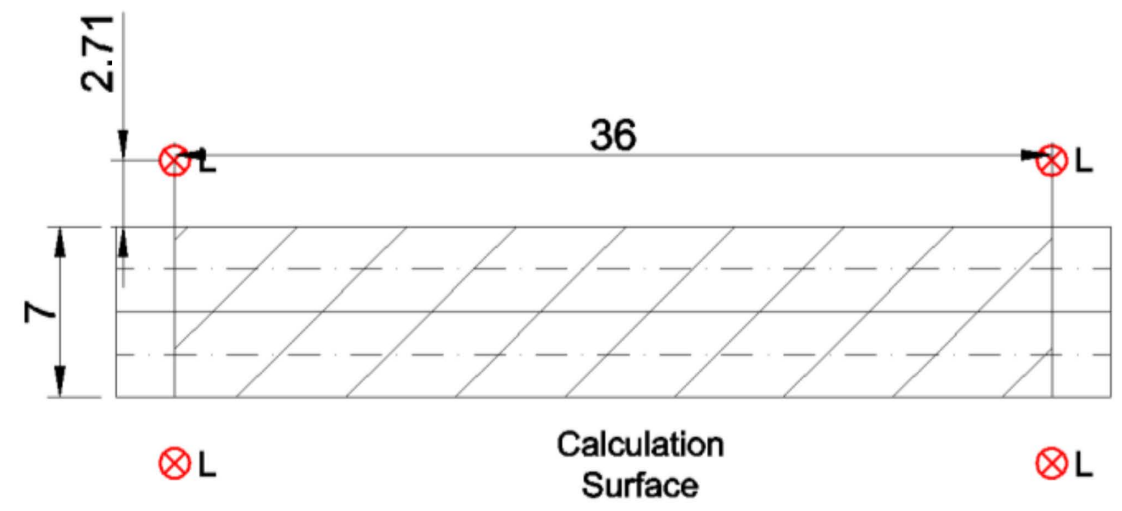

Figure 2. Geometry for the two-lanes road.

For other arrangements, the distance from the luminaire to the edge of the carriageway and the distance between the poles are identical. The luminaires used [20] are as follows:

- for the two-lanes carriageway: SCHREDER TECEO GEN 2 1/5244/24 LEDs $500 \mathrm{~mA}$ NW 740 37.6W/445172;

- $\quad$ for the four-lanes carriageway: SCHREDER TECEO GEN2 1/5244/32 LEDs 500 mA NW 740 50W/445172;

- $\quad$ for the six-lanes carriageway: SCHREDER TECEO GEN2 2/5103/56 LEDs $500 \mathrm{~mA}$ NW 740 85W// 456732.

Another difference observed between the two standards are the number of calculation points considered automatically by the programs; this is why, for this particular case study, we preset the number of calculation points in order to match each other.

Using the geometry in Figure 2, we have given all the calculations needed in order to evaluate the average luminance values calculated as per the two standards.

Considering the recommendation from [21] to have a calculation grid as large as possible, we have considered a gradual increase in the number of calculation points until they no longer have an effect on the average luminance value.

After analyzing the results in Table 1, for this particular case study, one can see that the average value can differ depending on the way of positioning the observer with even $17 \%$. Considering that the calculation grid was set gradually and that the calculations were performed only for a few lighting intensity distribution curves, one can conclude that in street lighting design projects, the error can be even larger. The difference between the two standards is dependent on the $\mathrm{I}(\mathrm{C}, \gamma)$ value, the lighting intensity incident in the direction of the calculation points. If this value is bigger in the direction where the $\beta$ angles are different, the average luminance and uniformity also differ more.

Table 1. Average luminance comparison between BS-EN 13201-3 and RP-08 standards.

\begin{tabular}{|c|c|c|c|c|c|c|c|c|c|c|}
\hline \multirow{2}{*}{$\begin{array}{l}\text { Calculated } \\
\text { Value }\end{array}$} & \multirow[t]{2}{*}{ Arrangement } & \multicolumn{3}{|c|}{$\begin{array}{c}\mathrm{L}_{\mathrm{av}} \text {-Two Lanes } \\
\text { Tilt Angle }\end{array}$} & \multicolumn{3}{|c|}{$\begin{array}{c}\mathbf{L}_{\mathrm{av}} \text {-Four Lanes } \\
\text { Tilt Angle }\end{array}$} & \multicolumn{3}{|c|}{$\begin{array}{l}\mathrm{L}_{\mathrm{av}}-\mathrm{Six} \text { Lanes } \\
\text { Tilt Angle }\end{array}$} \\
\hline & & $0^{\circ}$ & $10^{\circ}$ & $20^{\circ}$ & $0^{\circ}$ & $10^{\circ}$ & $20^{\circ}$ & $0^{\circ}$ & $10^{\circ}$ & $20^{\circ}$ \\
\hline \multirow{3}{*}{$\begin{array}{c}\mathrm{L}_{\mathrm{av1}} \\
\text { BS-EN 13201-3 } \\
\left(\mathrm{cd} / \mathrm{m}^{2}\right)\end{array}$} & Opposite & 0.92 & 1.11 & 1.12 & 0.77 & 0.98 & 1.08 & 0.99 & 1.11 & 1.11 \\
\hline & Staggered & 0.92 & 1.11 & 1.12 & 0.77 & 0.98 & 1.08 & 0.99 & 1.11 & 1.11 \\
\hline & Single sided & 0.42 & 0.51 & 0.52 & 0.32 & 0.4 & 0.45 & 0.4 & 0.45 & 0.45 \\
\hline \multirow{3}{*}{$\begin{array}{c}\mathrm{L}_{\mathrm{av} 2} \\
\mathrm{RP}-8-18 \\
\left(\mathrm{~cd} / \mathrm{m}^{2}\right)\end{array}$} & Opposite & 0.86 & 1.06 & 1.08 & 0.66 & 0.85 & 0.95 & 0.85 & 0.96 & 0.97 \\
\hline & Staggered & 0.86 & 1.06 & 1.08 & 0.66 & 0.85 & 0.95 & 0.85 & 0.96 & 0.97 \\
\hline & Single sided & 0.43 & 0.53 & 0.54 & 0.33 & 0.43 & 0.48 & 0.43 & 0.48 & 0.49 \\
\hline \multirow{3}{*}{$\frac{\mathrm{L}_{\mathrm{av} 1}}{\mathrm{~L}_{\mathrm{av} 2}}$} & Opposite & 1.07 & 1.05 & 1.04 & 1.17 & 1.15 & 1.14 & 1.16 & 1.16 & 1.14 \\
\hline & Staggered & 1.07 & 1.05 & 1.04 & 1.17 & 1.15 & 1.14 & 1.16 & 1.16 & 1.14 \\
\hline & Single sided & 0.98 & 0.96 & 0.96 & 0.97 & 0.93 & 0.94 & 0.93 & 0.94 & 0.92 \\
\hline
\end{tabular}


Considering that the average luminance for the two standards is not the same, the minimum and maximum values from the two standards calculations are not equal either; therefore, the uniformity will also be affected. In order to check whether the observer's positioning is the only parameter that differs, we conceived two scripts for an average luminance calculation. Unlike the design software, in the scripts, the observer's position can be set anywhere by the user.

The first step of the case study was to validate the program. The scripts were compared with multiple calculations for different arrangements, distribution curves and tilts performed in Dialux 4.13 according to the BS-EN and RP-08 standards. The observer's position for BS-EN was set in each center line, at $60 \mathrm{~m}$ from the calculation surface. The maximum error encountered in any of the calculations was $0.02 \mathrm{~cd} / \mathrm{m}^{2}$, according to Table 2, which most probably was due to the rounding of the values. When comparing the results for RP-08, they are equally encouraging. The maximum difference between the design software and the script is also $0.02 \mathrm{~cd} / \mathrm{m}^{2}$.

Table 2. Comparison between the design software and the script for the two-lanes carriageway.

\begin{tabular}{cccccccc}
\hline \multirow{2}{*}{$\begin{array}{c}\text { Tilt } \\
\text { Angle }\end{array}$} & Arrangement & \multicolumn{2}{c}{ BS-EN 13201 } & \multicolumn{2}{c}{$\mathbf{L}_{\mathbf{a v}}\left(\mathbf{c d} / \mathbf{m}^{\mathbf{2}}\right)$} & RP-08 & \\
& & $\begin{array}{c}\text { Dialux } \\
\mathbf{4 . 1 3}\end{array}$ & Script & $\begin{array}{c}\text { Error } \\
{[\%]}\end{array}$ & $\begin{array}{c}\text { Dialux } \\
\mathbf{4 . 1 3}\end{array}$ & $\begin{array}{c}\text { Script } \\
\text { Error } \\
{[\%]}\end{array}$ \\
\hline \multirow{2}{*}{$0^{\circ}$} & Opposite & 0.92 & 0.92 & 0 & 0.87 & 0.86 & 1.16 \\
& Staggered & 0.92 & 0.92 & 0 & 0.87 & 0.86 & 1.16 \\
& Single sided & 0.42 & 0.42 & 0 & 0.44 & 0.43 & 2.32 \\
\hline \multirow{2}{*}{$10^{\circ}$} & Opposite & 1.11 & 1.11 & 0 & 1.06 & 1.04 & 1.92 \\
& Staggered & 1.11 & 1.11 & 0 & 1.06 & 1.04 & 1.92 \\
& Single sided & 0.51 & 0.51 & 0 & 0.53 & 0.52 & 1.92 \\
\hline \multirow{2}{*}{$20^{\circ}$} & Opposite & 1.12 & 1.14 & 1.8 & 1.08 & 1.08 & 0 \\
& Staggered & 1.12 & 1.14 & 1.8 & 1.08 & 1.08 & 0 \\
& Single sided & 0.52 & 0.53 & 1.9 & 0.54 & 0.54 & 0 \\
\hline
\end{tabular}

After confirming that the program calculates the average luminance exactly as the design software, we made other sets of calculations in order to evaluate the observer's position influence on the average luminance values.

\section{The Influence of Longitudinal Observer Position in Luminance Calculation}

As in [22], the stopping distance can be considered for observer positioning. Official documents from different countries present different stopping distances for a dry pavement and the same traffic, as centralized in Table 3 [23].

Table 3. Stopping distance at different driving speed.

\begin{tabular}{cccccc}
\hline & & \multicolumn{4}{c}{ Stopping Distance on Dry Pavement for Different Countries (m) } \\
& Speed $\mathbf{( k m} / \mathbf{h})$ & France & Italy & Sweden & Switzerland \\
\hline Urban & 30 & 13 & 22 & 16 & $16-22$ \\
Roads & 50 & 28 & 55 & 38 & $34-48$ \\
Interurban & 90 & 70 & 136 & 121 & $88-115$ \\
Roads & 120 & 112 & 235 & 222 & $144-189$ \\
\hline
\end{tabular}

Considering these values, one can assume that the observer's position must be adjusted in order to be at a longer distance than the stopping distance for the speed limit of each road. The standards do consider the speed limit of the road as a parameter of choosing the lighting class [4], but they only allow for a bigger luminance level for high-speed roads.

Actually, the standard used for the design of lighting for road tunnels and underpasses [22] already references stopping distances. The recommendations set the reference 
point at a height of $1.5 \mathrm{~m}$ and at a distance from the entrance of the tunnel equal to the stopping distance at the design speed for each site, including the slope of the road.

The role of this paper is to see how the observer's position influences the luminance value, considering different distances from the calculation surface.

By using the scripts mentioned in the previous chapter, we made calculations with the observer placed at different distances, starting from a 10-meters distance to 90-m distance with increments of $10 \mathrm{~m}$.

For the input, the authors have used the following data:

- the height of the luminaire: $10 \mathrm{~m}$;

- distance from the edge of the carriageway to the luminaire is always $2.71 \mathrm{~m}$;

- $\quad$ asphalt type: R3;

- maintenance factor: 1.

For the study to be more conclusive, it was made for two types of roads, a two-lanes carriageway and a six-lanes carriageway.

As in the previous case-study, the luminaire used for the two-lanes carriageway is SCHREDER TECEO GEN 2 1/5244/24LEDs 500 mA NW 740 37.6W/445172, while for the six-lanes the authors have used SCHREDER TECEO GEN2 2512156 LEDs $500 \mathrm{~mA}$ NW 740 4000K Ra70 85W 456862. The study was made for both European and American standards in order to calculate the average luminance.

European [11] and American [12] street lighting design standards define very clearly the observer positioning. After analyzing this information in detail, the conclusion is that this particular parameter is treated very differently between the two standards.

The present case study determines the problems encountered in street lighting calculation when using each of the standards' observer positioning.

The first part of the case study refers to RP-08 [12], which states that the observer is located at a distance of $83.07 \mathrm{~m}$ for each calculation point on a line parallel to the center axes of the road. Considering Figure 3's geometry, this actually means that regardless of the angle of observation and the observer's distance to the calculation point, the results are exactly the same. This theory is based on the fact that $\gamma, \beta$ and $\phi$ will not change at all if the observer is always in a straight line with the calculation point, and that only $\alpha$ is changing. This means that there is no need for extra calculations in order to confirm this hypothesis.

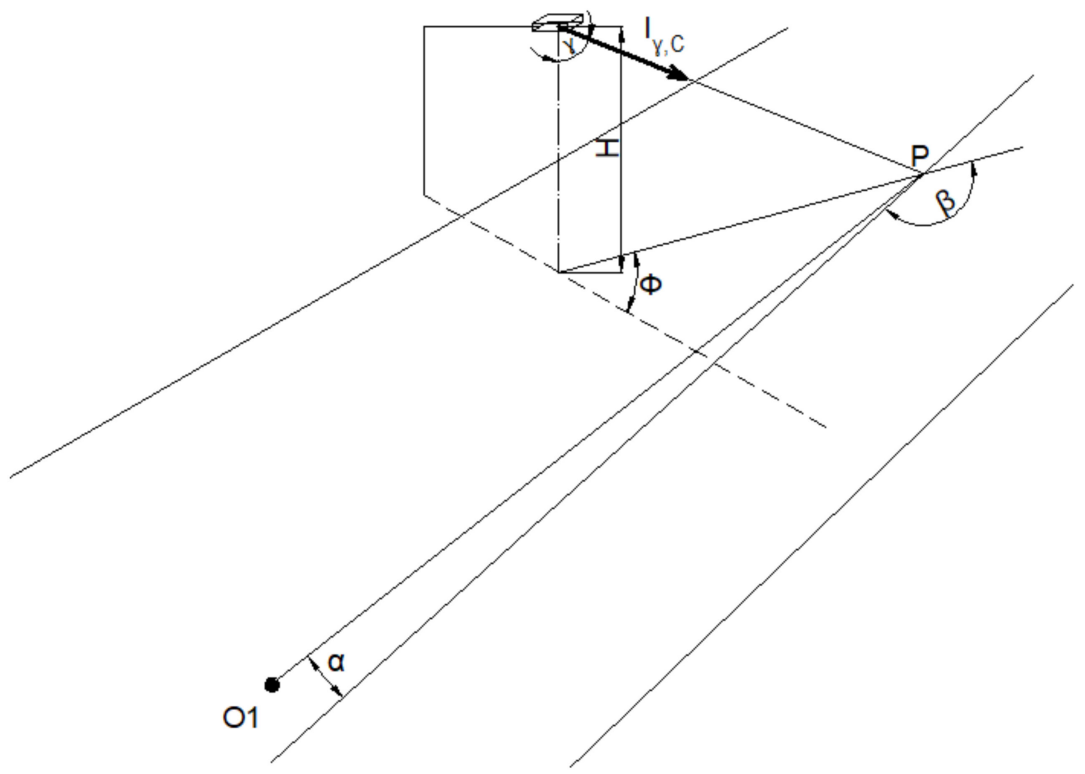

Figure 3. Orientation for illuminance and luminance calculation according to RP-08.

The fact that the luminance values do not change depending on the distance from the calculation point to the observer raises a very big question mark on the way luminance is 
calculated according to RP-08. The observer needs to see the entire road in order to assess the risk properly and to see any pedestrians or other vehicles on the road.

According to [16], changing the angle of observation directly affects the average luminance on a road. They also conclude that the European standard needs to be updated in order to add extra angles of observation according to the type of road.

The present paper will not try to define the angles on which the calculations should be performed, but will present the differences between the average luminance calculations performed with the standardized observer position of $60 \mathrm{~m}$ and the calculations performed for other distances in the $10-90 \mathrm{~m}$ interval, with an increment of $10 \mathrm{~m}$, as presented in Figure 4.

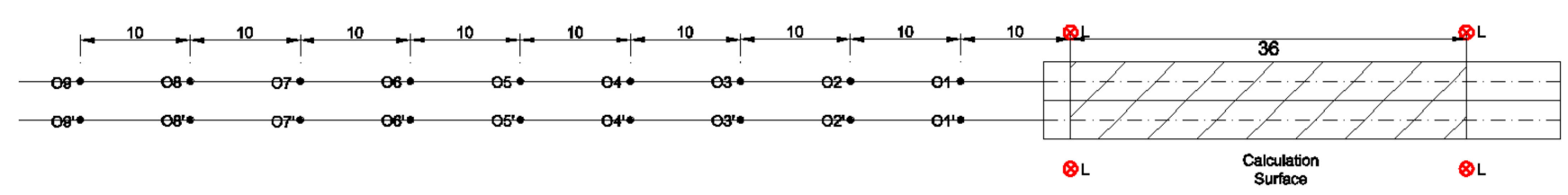

Figure 4. Geometry of the installation for average luminance calculation with different observer positioning.

All the calculations are made for two types of carriageways, a two-lanes carriageway and a six-lanes carriageway, and for the following three arrangement types: opposite, staggered and single sided at a $0^{\circ}, 10^{\circ}$ and $20^{\circ}$ tilt.

Table 4 presents the centralization of the average luminance for the two-lanes carriageway, while Table 5 presents the centralization of the results for the six-lane.

Table 4. Two-lanes road, average luminance comparison in relate to longitudinal observer positioning as per BS-EN 13201.

\begin{tabular}{|c|c|c|c|c|c|c|c|c|c|c|c|}
\hline \multirow{2}{*}{$\begin{array}{c}\text { Asphalt } \\
\text { Type }\end{array}$} & \multirow[b]{2}{*}{ Tilt } & \multirow[b]{2}{*}{ Arrangement } & \multicolumn{9}{|c|}{ Tilt Angle } \\
\hline & & & \multicolumn{9}{|c|}{$\mathrm{L}_{\mathrm{av}}\left(\mathrm{cd} / \mathrm{m}^{2}\right)$} \\
\hline \multirow{9}{*}{$\mathrm{R} 1$} & \multirow{3}{*}{$0^{\circ}$} & Opposite & 1.29 & 1.29 & 1.29 & 1.29 & 1.29 & 1.29 & 1.29 & 1.28 & 1.28 \\
\hline & & Staggered & 1.29 & 1.29 & 1.29 & 1.29 & 1.29 & 1.29 & 1.29 & 1.28 & 1.28 \\
\hline & & Single sided & 0.63 & 0.63 & 0.63 & 0.63 & 0.63 & 0.63 & 0.63 & 0.63 & 0.63 \\
\hline & \multirow{3}{*}{$10^{\circ}$} & Opposite & 1.59 & 1.59 & 1.59 & 1.59 & 1.59 & 1.59 & 1.59 & 1.59 & 1.59 \\
\hline & & Staggered & 1.6 & 1.6 & 1.6 & 1.6 & 1.6 & 1.6 & 1.59 & 1.59 & 1.59 \\
\hline & & Single sided & 0.77 & 0.78 & 0.78 & 0.78 & 0.78 & 0.78 & 0.78 & 0.78 & 0.78 \\
\hline & \multirow{3}{*}{$20^{\circ}$} & Opposite & 1.69 & 1.69 & 1.69 & 1.69 & 1.69 & 1.69 & 1.69 & 1.69 & 1.69 \\
\hline & & Staggered & 1.69 & 1.69 & 1.69 & 1.69 & 1.69 & 1.69 & 1.69 & 1.69 & 1.69 \\
\hline & & Single sided & 0.82 & 0.83 & 0.83 & 0.83 & 0.83 & 0.83 & 0.83 & 0.83 & 0.83 \\
\hline \multirow{9}{*}{$\mathrm{R} 2$} & \multirow{3}{*}{$0^{\circ}$} & Opposite & 0.97 & 0.97 & 0.97 & 0.96 & 0.95 & 0.95 & 0.94 & 0.94 & 0.93 \\
\hline & & Staggered & 0.97 & 0.97 & 0.97 & 0.96 & 0.95 & 0.95 & 0.94 & 0.94 & 0.93 \\
\hline & & Single sided & 0.45 & 0.45 & 0.45 & 0.45 & 0.45 & 0.45 & 0.45 & 0.45 & 0.45 \\
\hline & \multirow{3}{*}{$10^{\circ}$} & Opposite & 1.17 & 1.17 & 1.17 & 1.16 & 1.15 & 1.15 & 1.14 & 1.14 & 1.13 \\
\hline & & Staggered & 1.18 & 1.17 & 1.17 & 1.16 & 1.15 & 1.15 & 1.14 & 1.14 & 1.13 \\
\hline & & Single sided & 0.54 & 0.54 & 0.54 & 0.54 & 0.54 & 0.54 & 0.54 & 0.54 & 0.54 \\
\hline & \multirow{3}{*}{$20^{\circ}$} & Opposite & 1.21 & 1.22 & 1.22 & 1.21 & 1.2 & 1.2 & 1.19 & 1.19 & 1.19 \\
\hline & & Staggered & 1.21 & 1.22 & 1.21 & 1.21 & 1.2 & 1.2 & 1.19 & 1.19 & 1.19 \\
\hline & & Single sided & 0.56 & 0.56 & 0.56 & 0.57 & 0.57 & 0.57 & 0.57 & 0.57 & 0.57 \\
\hline \multirow{9}{*}{ R3 } & \multirow{4}{*}{$0^{\circ}$} & Opposite & 0.97 & 0.97 & 0.96 & 0.95 & 0.94 & 0.93 & 0.92 & 0.91 & 0.91 \\
\hline & & Staggered & 0.98 & 0.97 & 0.96 & 0.95 & 0.94 & 0.93 & 0.92 & 0.91 & 0.91 \\
\hline & & Single sided & 0.43 & 0.43 & 0.43 & 0.43 & 0.43 & 0.43 & 0.43 & 0.43 & 0.43 \\
\hline & & Opposite & 1.15 & 1.15 & 1.14 & 1.12 & 1.11 & 1.1 & 1.1 & 1.09 & 1.09 \\
\hline & \multirow[t]{2}{*}{$10^{\circ}$} & Staggered & 1.15 & 1.15 & 1.14 & 1.12 & 1.11 & 1.1 & 1.1 & 1.09 & 1.09 \\
\hline & & Single sided & 0.51 & 0.51 & 0.51 & 0.51 & 0.51 & 0.51 & 0.51 & 0.51 & 0.51 \\
\hline & \multirow{3}{*}{$20^{\circ}$} & Opposite & 1.18 & 1.18 & 1.17 & 1.16 & 1.15 & 1.14 & 1.13 & 1.13 & 1.12 \\
\hline & & Staggered & 1.18 & 1.18 & 1.17 & 1.16 & 1.15 & 1.14 & 1.13 & 1.13 & 1.12 \\
\hline & & Single sided & 0.52 & 0.52 & 0.52 & 0.52 & 0.53 & 0.53 & 0.53 & 0.53 & 0.53 \\
\hline
\end{tabular}


Table 4. Cont.

\begin{tabular}{|c|c|c|c|c|c|c|c|c|c|c|c|}
\hline \multirow{2}{*}{$\begin{array}{c}\text { Asphalt } \\
\text { Type }\end{array}$} & \multirow[b]{2}{*}{ Tilt } & \multirow[b]{2}{*}{ Arrangement } & \multicolumn{9}{|c|}{ Tilt Angle } \\
\hline & & & \multicolumn{9}{|c|}{$\mathrm{L}_{\mathrm{av}}\left(\mathrm{cd} / \mathrm{m}^{2}\right)$} \\
\hline \multirow{9}{*}{$\mathrm{R} 4$} & \multirow{3}{*}{$0^{\circ}$} & Opposite & 1.1 & 1.1 & 1.09 & 1.07 & 1.05 & 1.04 & 1.02 & 1.01 & 1.01 \\
\hline & & Staggered & 1.1 & 1.1 & 1.09 & 1.07 & 1.05 & 1.04 & 1.02 & 1.01 & 1.01 \\
\hline & & Single sided & 0.47 & 0.46 & 0.46 & 0.46 & 0.46 & 0.46 & 0.46 & 0.46 & 0.46 \\
\hline & \multirow{3}{*}{$10^{\circ}$} & Opposite & 1.28 & 1.29 & 1.28 & 1.26 & 1.24 & 1.23 & 1.21 & 1.2 & 1.2 \\
\hline & & Staggered & 1.28 & 1.29 & 1.27 & 1.26 & 1.24 & 1.23 & 1.22 & 1.2 & 1.2 \\
\hline & & Single sided & 0.54 & 0.54 & 0.54 & 0.54 & 0.55 & 0.55 & 0.55 & 0.55 & 0.55 \\
\hline & \multirow{3}{*}{$20^{\circ}$} & Opposite & 1.31 & 1.31 & 1.3 & 1.29 & 1.28 & 1.26 & 1.25 & 1.24 & 1.23 \\
\hline & & Staggered & 1.31 & 1.32 & 1.3 & 1.29 & 1.28 & 1.26 & 1.25 & 1.24 & 1.24 \\
\hline & & Single sided & 0.55 & 0.56 & 0.56 & 0.56 & 0.57 & 0.57 & 0.57 & 0.57 & 0.57 \\
\hline
\end{tabular}

Table 5. Six-lanes road, average luminance comparison in relate to longitudinal observer positioning as per BS-EN 13201.

\begin{tabular}{|c|c|c|c|c|c|c|c|c|c|c|c|}
\hline \multirow{2}{*}{$\begin{array}{c}\text { Asphalt } \\
\text { Type }\end{array}$} & \multirow[b]{2}{*}{ Tilt } & \multirow[b]{2}{*}{ Arrangement } & \multicolumn{9}{|c|}{ Tilt Angle } \\
\hline & & & \multicolumn{9}{|c|}{$\mathrm{L}_{\mathrm{av}}\left(\mathrm{cd} / \mathrm{m}^{2}\right)$} \\
\hline \multirow{9}{*}{$\mathrm{R} 1$} & \multirow{3}{*}{$0^{\circ}$} & Opposite & 1.53 & 1.53 & 1.52 & 1.52 & 1.52 & 1.52 & 1.51 & 1.51 & 1.51 \\
\hline & & Staggered & 1.53 & 1.53 & 1.52 & 1.52 & 1.52 & 1.52 & 1.51 & 1.51 & 1.51 \\
\hline & & Single sided & 0.77 & 0.76 & 0.75 & 0.75 & 0.75 & 0.75 & 0.75 & 0.75 & 0.75 \\
\hline & \multirow{3}{*}{$10^{\circ}$} & Opposite & 1.35 & 1.34 & 1.34 & 1.34 & 1.33 & 1.33 & 1.33 & 1.33 & 1.33 \\
\hline & & Staggered & 1.35 & 1.35 & 1.34 & 1.34 & 1.33 & 1.33 & 1.33 & 1.33 & 1.33 \\
\hline & & Single sided & 0.67 & 0.67 & 0.66 & 0.66 & 0.66 & 0.66 & 0.66 & 0.66 & 0.66 \\
\hline & \multirow{3}{*}{$20^{\circ}$} & Opposite & 1.07 & 1.06 & 1.06 & 1.06 & 1.06 & 1.06 & 1.05 & 1.05 & 1.05 \\
\hline & & Staggered & 1.07 & 1.07 & 1.07 & 1.06 & 1.06 & 1.06 & 1.06 & 1.06 & 1.05 \\
\hline & & Single sided & 0.53 & 0.52 & 0.52 & 0.52 & 0.52 & 0.52 & 0.52 & 0.52 & 0.52 \\
\hline \multirow{9}{*}{$\mathrm{R} 2$} & \multirow{3}{*}{$0^{\circ}$} & Opposite & 0.97 & 0.96 & 0.96 & 0.95 & 0.95 & 0.94 & 0.94 & 0.93 & 0.93 \\
\hline & & Staggered & 0.97 & 0.96 & 0.96 & 0.95 & 0.95 & 0.94 & 0.94 & 0.93 & 0.93 \\
\hline & & Single sided & 0.45 & 0.45 & 0.45 & 0.45 & 0.45 & 0.45 & 0.45 & 0.45 & 0.45 \\
\hline & \multirow{3}{*}{$10^{\circ}$} & Opposite & 0.86 & 0.85 & 0.84 & 0.84 & 0.83 & 0.82 & 0.82 & 0.82 & 0.81 \\
\hline & & Staggered & 0.86 & 0.85 & 0.84 & 0.84 & 0.83 & 0.83 & 0.82 & 0.82 & 0.81 \\
\hline & & Single sided & 0.4 & 0.39 & 0.39 & 0.39 & 0.39 & 0.39 & 0.39 & 0.39 & 0.39 \\
\hline & \multirow{3}{*}{$20^{\circ}$} & Opposite & 0.69 & 0.69 & 0.69 & 0.68 & 0.68 & 0.67 & 0.67 & 0.67 & 0.66 \\
\hline & & Staggered & 0.7 & 0.69 & 0.69 & 0.68 & 0.68 & 0.67 & 0.67 & 0.67 & 0.66 \\
\hline & & Single sided & 0.31 & 0.31 & 0.31 & 0.31 & 0.31 & 0.31 & 0.31 & 0.31 & 0.31 \\
\hline \multirow{9}{*}{ R3 } & \multirow{3}{*}{$0^{\circ}$} & Opposite & 0.83 & 0.82 & 0.81 & 0.81 & 0.8 & 0.8 & 0.79 & 0.79 & 0.78 \\
\hline & & Staggered & 0.83 & 0.82 & 0.81 & 0.81 & 0.8 & 0.8 & 0.79 & 0.79 & 0.78 \\
\hline & & Single sided & 0.3 & 0.3 & 0.31 & 0.31 & 0.31 & 0.31 & 0.31 & 0.31 & 0.31 \\
\hline & \multirow{3}{*}{$10^{\circ}$} & Opposite & 0.75 & 0.74 & 0.73 & 0.72 & 0.72 & 0.71 & 0.71 & 0.7 & 0.7 \\
\hline & & Staggered & 0.75 & 0.74 & 0.73 & 0.72 & 0.72 & 0.71 & 0.71 & 0.7 & 0.7 \\
\hline & & Single sided & 0.3 & 0.31 & 0.31 & 0.31 & 0.31 & 0.32 & 0.32 & 0.32 & 0.32 \\
\hline & \multirow{3}{*}{$20^{\circ}$} & Opposite & 0.62 & 0.62 & 0.62 & 0.61 & 0.61 & 0.6 & 0.6 & 0.59 & 0.59 \\
\hline & & Staggered & 0.62 & 0.62 & 0.61 & 0.61 & 0.61 & 0.6 & 0.6 & 0.59 & 0.59 \\
\hline & & Single sided & 0.25 & 0.25 & 0.26 & 0.26 & 0.26 & 0.26 & 0.26 & 0.26 & 0.26 \\
\hline \multirow{9}{*}{$\mathrm{R} 4$} & \multirow{3}{*}{$0^{\circ}$} & Opposite & 0.81 & 0.8 & 0.79 & 0.78 & 0.78 & 0.77 & 0.76 & 0.76 & 0.75 \\
\hline & & Staggered & 0.81 & 0.8 & 0.79 & 0.78 & 0.78 & 0.77 & 0.76 & 0.76 & 0.75 \\
\hline & & Single sided & 0.33 & 0.33 & 0.33 & 0.33 & 0.33 & 0.33 & 0.33 & 0.34 & 0.34 \\
\hline & \multirow{3}{*}{$10^{\circ}$} & Opposite & 0.74 & 0.73 & 0.72 & 0.71 & 0.7 & 0.69 & 0.69 & 0.68 & 0.67 \\
\hline & & Staggered & 0.74 & 0.73 & 0.72 & 0.71 & 0.7 & 0.69 & 0.69 & 0.68 & 0.67 \\
\hline & & Single sided & 0.29 & 0.29 & 0.29 & 0.29 & 0.3 & 0.3 & 0.3 & 0.3 & 0.3 \\
\hline & \multirow{3}{*}{$20^{\circ}$} & Opposite & 0.63 & 0.63 & 0.62 & 0.62 & 0.61 & 0.6 & 0.6 & 0.59 & 0.59 \\
\hline & & Staggered & 0.63 & 0.63 & 0.62 & 0.62 & 0.61 & 0.6 & 0.6 & 0.59 & 0.59 \\
\hline & & Single sided & 0.24 & 0.24 & 0.24 & 0.25 & 0.25 & 0.25 & 0.25 & 0.25 & 0.25 \\
\hline
\end{tabular}


After analyzing the results from the two tables, one can see that for the luminaires used in the case study, there are some differences in the results, especially for the symmetric arrangements. Based on the two tables, one can calculate the maximum error for the two arrangements in this particular case-study.

By comparing the minimum with the maximum average luminance, we calculated the errors that could occur due to the change in the observer's positioning. For these two particular arrangements and luminaires, the maximum error is $9.46 \%$ for the six-lanes carriageway, for staggered arrangement, at $10^{\circ}$ tilt and $\mathrm{R} 4$ asphalt.

Considering that each calculation is made only for one distribution curve, in practice, the error could actually be much higher in some cases. Even if these values are not spectacular, they could be important for the dimming strategy in street lighting.

Considering this, it would be of interest that standards update the luminance calculation in order to match the requirements of each particular road and country, based on stopping distance conditions. If this parameter were not to be included as an option, it is clear that high speed roads could be underlit even if the design criteria are met for symmetric arrangements.

The surprise comes at single sided arrangements where, regardless of the observer positioning, in the few cases considered, it seems that there is very little change in the luminance values if the distance from the observer to the calculation surface changes. To check if they do not represent particular cases, this theory needed to be checked in the field, based on luminance measurements.

\section{Case Study Regarding the Influence of Longitudinal Observer Position in Luminance Measurements}

It is well known that the asphalt type can have a big influence on luminance values $[17,18]$. Studies show that the average luminance for dark asphalt can only be $30 \%$ of the value obtained for a light one [19]. Measurements could be performed in the field to determine the real reduced luminance coefficient [24-26], but this would mean closing the road to the traffic for an unacceptable time. Imaging measurements can also be used in order to calculate the reflectance properties of the asphalt, just as the authors have demonstrated in the paper [27].

The calculations performed in the previous case study demonstrate that the distance from the observer to the calculation surface has little influence on the average luminance value for a single sided arrangement.

In practice, there is actually a big difference in light perception when approaching a certain area depending on the observer's position. This is why a thorough field analysis was needed to check whether the calculations matched the reality.

The case study consists of luminance measurements for the same street surfaces from different distances, between $10 \mathrm{~m}$ and $90 \mathrm{~m}$ with an increment of $10 \mathrm{~m}$.

Figure 5 presents the geometry of the street and the observer's positioning, while Figure 6 presents the luminance image with the camera positioned at $40 \mathrm{~m}$ from the calculation surface.

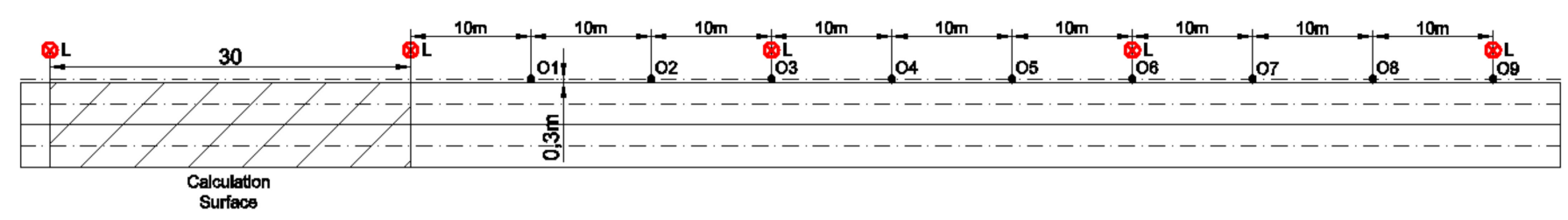

Figure 5. Geometry of the installation for different observer positioning. 


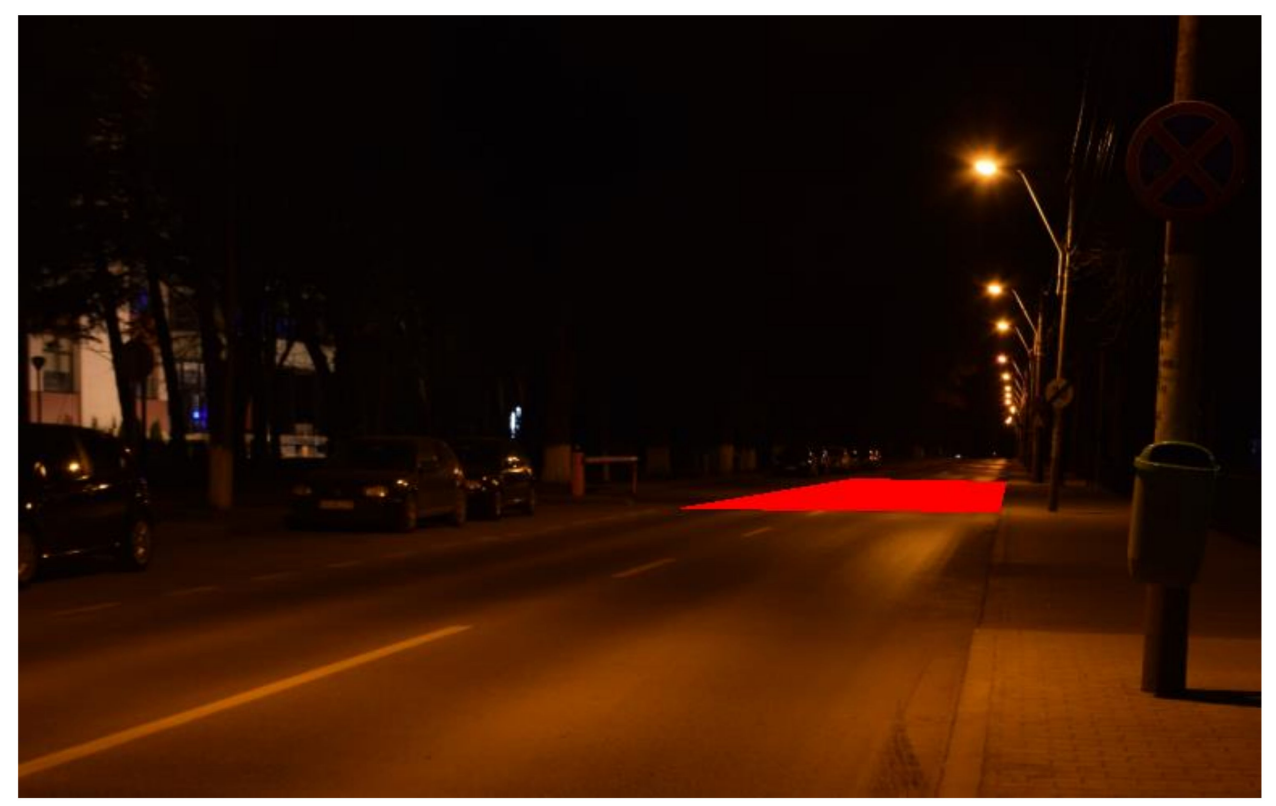

Figure 6. Luminance measurement from the image with the observer at $40 \mathrm{~m}$ from the calculation surface.

Table 6 centralizes the average luminance measured based on the images taken in the field with the camera positioned at different distances from the calculation surface. By comparing the value calculated based on the digital image taken at $10 \mathrm{~m}$ from the calculation surface with the one taken at $90 \mathrm{~m}$, one can see that there is more than a $50 \%$ increase when moving the camera further. The average luminance value calculated for R3 asphalt at different observer distances are almost the same, but from the measurements, the conclusion is that during the life of the asphalt, the reduced luminance coefficient can change drastically. Considering that the asphalt on which the measurements were made had a relatively low degree of wear, we can assume that if the asphalt had more wear, we could have observed even higher differences.

Table 6. Average luminance comparison for measurements conducted at different distances from observer to calculation surface.

\begin{tabular}{lcccccccccc}
\hline & \multicolumn{10}{c}{ Distance from the Observer to the Surface (m) } \\
& $\mathbf{1 0}$ & $\mathbf{2 0}$ & $\mathbf{3 0}$ & $\mathbf{4 0}$ & $\mathbf{5 0}$ & $\mathbf{6 0}$ & $\mathbf{7 0}$ & $\mathbf{8 0}$ & $\mathbf{9 0}$ \\
\hline $\mathrm{L}_{\mathrm{av}}\left(\mathrm{cd} / \mathrm{m}^{2}\right)$ & 1.80 & 1.89 & 2.13 & 2.17 & 2.33 & 2.47 & 2.54 & 2.71 & 2.75 \\
\hline
\end{tabular}

At a first look, the fact that the average luminance is so different represents a disadvantage, but actually the value increases. Due to the wear of the asphalt, the reflectance properties are very different, which means that we cannot rely on the standard values [28]. In order to properly assess the problem, we would need to periodically check the asphalt's reflection, for instance, yearly. Based on the field results, the dimming strategy of the installation can be adjusted in order to reduce the light intensity and consumption as much as possible. This is allowed as long as the standard average luminance value requirements are met.

For a better representation of Table 6, in Figure 7 one can see the luminance maps for each of the observer positions. The color scale for each luminance map is set exactly the same, so that one can visualize the changes that appear in the luminance values when moving the camera backwards. 


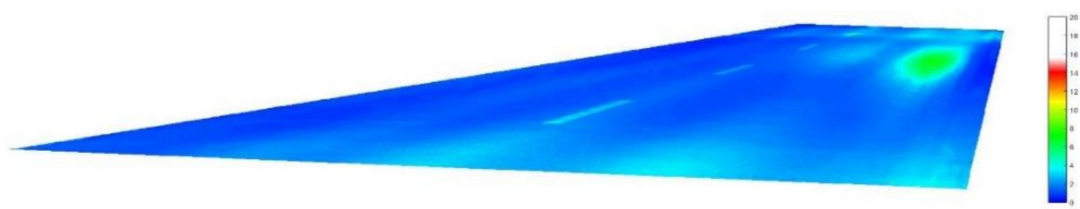

(a)

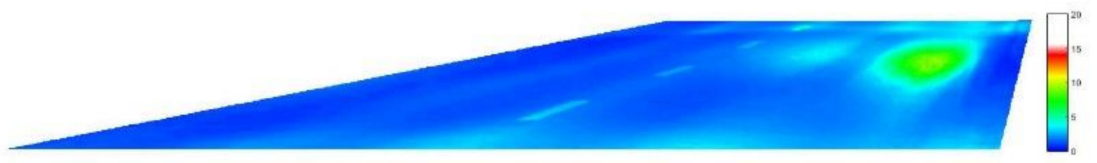

(b)

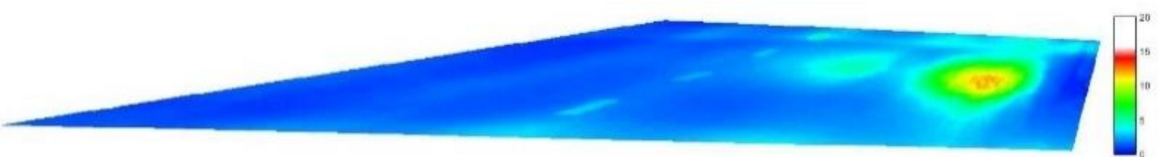

(c)

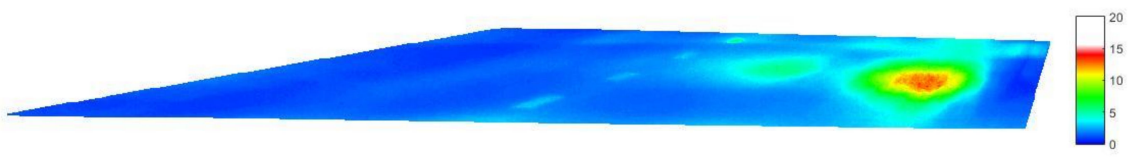

(d)

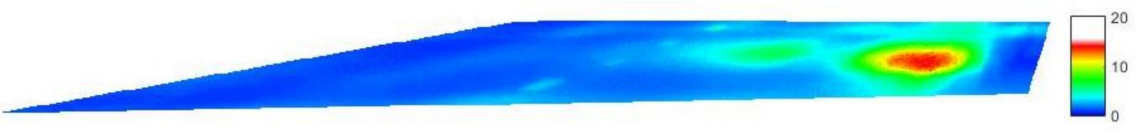

(e)

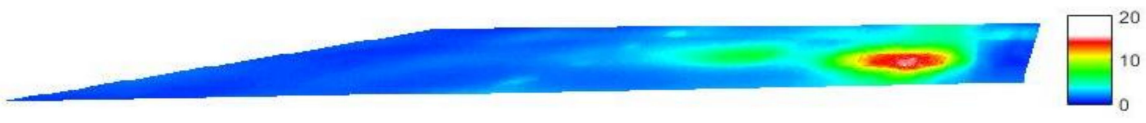

(f)

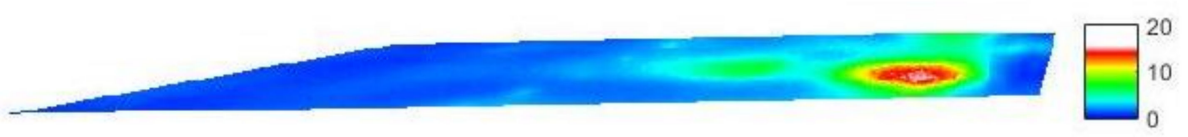

(g)

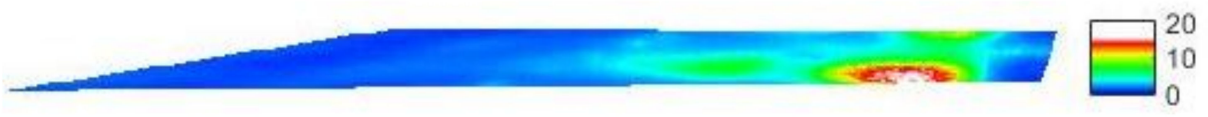

(h)

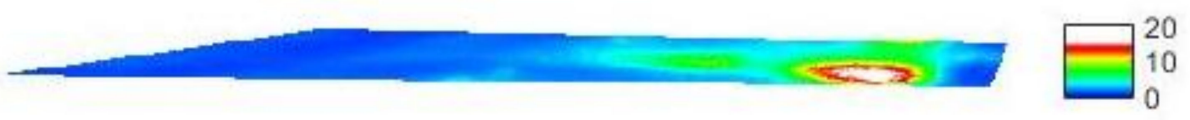

(i)

Figure 7. Luminance map variation for the observer positioned from the calculation surface at: (a) $10 \mathrm{~m}$, (b) $20 \mathrm{~m}$, (c) $30 \mathrm{~m}$, (d) $40 \mathrm{~m}$, (e) $50 \mathrm{~m}$, (f) $60 \mathrm{~m}$, (g) $70 \mathrm{~m}$, (h) $80 \mathrm{~m}$, (i) $90 \mathrm{~m}$.

Paper [29] presents a study in which, based on different parameters such as the maintenance factor, the declassification of roads and the real distance in the field between poles compared to the one designed, the performance of street lighting installations can be optimized through dimming. In the same way that those parameters represent a condition based on which luminaires can be dimmed, the same theory can be applied to the reflection 
factor of the asphalt with the condition that, if there are any footpaths, they need to comply with all the restrictions specified in the standards. This, along with the utilance factor (U) and installation lighting factor (ILF) [30], could have an important role in selecting the most appropriate luminaire, especially in the design phase. Studies have already presented automatic methods in selecting the most economical way of investing by analyzing street lighting subsystems with a dynamic programming approach $[31,32]$. Considering this, the importance of adapting the lighting systems to the speed of each road is much more important, because measurements conducted with the observer adjusted correspondingly to each particular road could be essential input data in order for the programming to give the best solution possible.

\section{Conclusions}

This paper proves that the methods of positioning the observer in the American and European standards are very different and can have a big influence when calculating the average luminance and uniformity.

We have reached the conclusion that observer positioning as per BS-EN 13201 standards reflect the field measurements more than RP08. This is why the recommendations are to conduct calculations with the observer at the center of each lane in turn and to select the minimum values for average luminance, overall uniformity, longitudinal luminance and the maximum threshold increment.

The results show that both standards can be improved. The American standard positions the observer according to each measured/calculated point on a line parallel to the road axis. This makes the luminance value insensitive to the distance from the observer to the calculation point. The European standard positions the observer at a fixed distance of $60 \mathrm{~m}$ from the calculation surface on each traffic lane center axis. The case study presented shows that, in reality, the average luminance can vary even by $50 \%$, a variation that means a reduction in the luminance level by even a class according to the street lighting standards, which is unacceptable. Based on field measurements, we have concluded that the reflectance properties of the asphalt can be very different from the ones considered in the standard and can influence the luminance values a lot, which will not only affect the average value on a surface, but the overall uniformity as well.

The field measurements have shown that it is essential not only to take into consideration the distance of the observer based on the speed limit, but also to conduct tests for the reflectance coefficient for different degrees of asphalt wear in order to make new luminance coefficient tables based on the usage of the asphalt.

Future research should analyze how the different types and degrees of wear of asphalt influence the average luminance value, in reference to the observer longitudinal positioning.

Considering that after any takeover of work the constructor should provide average luminance measurements, there should be no inconvenience to move the observer at the braking distance instead of the standard $60 \mathrm{~m}$.

Author Contributions: Conceptualization, A.V.R.; methodology, A.V.R., C.D.G. and D.D.L.; software, A.V.R.; validation, C.D.G. and D.D.L.; formal analysis, D.D.L. and G.L.; investigation, C.D.G. and A.V.R.; resources, C.D.G. and A.V.R.; data curation, A.V.R., C.D.G. and D.D.L.; writing-original draft preparation, A.V.R.; writing-review and editing, D.D.L., C.D.G. and G.L. All authors have read and agreed to the published version of the manuscript.

Funding: This work was supported by a publications' grant of the TUIASI, project number GI/P25/2021.

Institutional Review Board Statement: Not applicable.

Informed Consent Statement: Not applicable.

Data Availability Statement: The data are available from the corresponding author upon request.

Conflicts of Interest: The authors declare no conflict of interest. 


\section{References}

1. International Energy Agency (IEA). Light's a Labour's Lost, Policies for Energy Efficient Lighting; International Energy Agency: France, Paris, 2006.

2. Wojnicki, I.; Komnata, K.; Kotulski, L. Comparative Study of Road Lighting Efficiency in the Context of CEN/TR 132012004 and 2014 Lighting Standards and Dynamic Control. Energies 2019, 12, 1524. [CrossRef]

3. European Standard. Road Lighting_Part 1: Guidelines on Selection of Lighting Classes (EN 13201-1:2004); European Standard: Brussels, Belgium, 2004.

4. European Standard. Road Lighting_Part 1: Guidelines on Selection of Lighting Classes (EN 13201-1:2014); European Standard: Brussels, Belgium, 2015.

5. Rusu, A.V.; Lucache, D.D.; Galatanu, C.D. Study on Illuminance Class Selection in Street Lighting Design. In Proceedings of the 8th International Conference on Modern Power Systems (MPS), Cluj-Napoca, Romania, 21-23 May 2019. [CrossRef]

6. Djuretic, A.; Kostic, M. Actual Energy Savings When Replacing High-Pressure Sodium with LED Luminaires in Street Lighting. Energy J. 2018, 157, 367-373. [CrossRef]

7. European Union. EC Commission Regulation (EC) No 245/2009, Implementing Directive 2005/32/EC of the European Parliament and of the Council with Regard to Ecodesign Requirements for Fluorescent Lamps Without Integrated Ballast, for High Intensity Discharge Lamps and for Ballasts and Luminaires Able to Operate Such Lamps; European Union: Brussels, Belgium, 2009.

8. The European Parliament and the Council. Directive 2011/65/Eu of the European Parliament and of the Council of 8 June 2011 on the Restriction of the Use of Certain Hazardous Substances in Electrical and Electronic Equipment; The European Parliament and the Council: Brussels, Belgium, 2011; p. 1123.

9. European Standard. Road Lighting_Part 5: Energy Performance Indicators (EN 13201-5:2015); European Standard: Brussels, Belgium, 2015.

10. Pracki, P. A Proposal to Classify Road Lighting Energy Efficiency. Lighting Res. Technol. 2011, 43, 271-280. [CrossRef]

11. European Standard. Road Lighting_Part 2: Performance Requirements (EN 13201-2:2015); European Standard: Brussels, Belgium, 2015.

12. ANSI. American National Standards Practice for Design and Maintenance of Roadway and Parking Facility Lighting (RP-8-18); ANSI: Washington, DC, USA, 2018; ISBN 978-0-87995-382-9.

13. Technical University of Constructions Bucharest, Faculty of Installations. Standard for the Design of Road and Pedestrian Lighting Systems (NP 062); Matrix Rom: Bucharest, Romania, 2002.

14. Handbook Street Lighting Construction and Planning, Road Standards Group "Equipment for roads and structures", Denmark, April 2015. Available online: http:/ / english-vejregler.lovportaler.dk/showdoc.aspx?schultzlink=vde-2015-0069\#pkt0.3 (accessed on 30 August 2021).

15. European Standard. Road Lighting_Part 3: Calculation of Performance (EN 13201-3:2015); European Standard: Brussels, Belgium, 2015.

16. Muzet, V.; Bernasconi, J.; Iacomussi, P.; Liandrat, S.; Greffier, F.; Blattner, P.; Reber, J.; Lindgren, J. Review of Road Surface Photometry Methods and Devices-Proposal for new Measurement Geometries. Lighting Res. Technol. 2020, 53, $213-229$. [CrossRef]

17. Fotios, S.; Boyce, P.; Ellis, C. The Effect of Pavement Material on Road Lighting Performance. Lighiting J. 2006, 71, 35.

18. Ekrias, A.; Ylinen, A.; Eloholma, M.; Halonen, M. Effects of Pavement Lightness and Colour on Road Lighting Performance. In Proceedings of the CIE International Symposium on Road Surface Photometric Characteristics: Measurement Systems and Results, Torino, Italy, 9-10 July 2008.

19. Gidlung, H.; Lindgren, M.; Muzet, V.; Rossi, G.; Iacomussi, P. Road Surface Photometric Characterisation and Its Impact on Energy Savings. Coatings 2019, 9, 286. [CrossRef]

20. SCHRéDER Experts in Lightability. Available online: https:/ /www.schreder.com/en/products/teceo-led-street-lighting (accessed on 1 March 2021).

21. Lipnický, L.; Gašparovský, D.; Dubnička, R. Influence of the Calculation Grid Density to the Selected Photometric Parameters for Road Lighting. In Proceedings of the Lighting Conference of the Visegrad Countries (Lumen V4), Karpacz, Poland, 13-16 September 2016. [CrossRef]

22. Commission Internationale de l'Éclairage (CIE). Guide for the Lighting of Road Tunnels and Underpasses, 2nd ed.; (CIE 088); Commission Internationale de l'Éclairage: Vienna, Austria, 2004.

23. Greffier, F.; Muzet, V.; Boucher, V.; Fournela, F.; Dronneau, R. Use of an Imaging Luminance Measuring Device to Evaluate Road Lighting Performance at Different Angles of Observation, Commision Internationale de l'Eclairage. In Proceedings of the 29th CIE Session 2019, Washington, DC, USA, 14-22 June 2019. [CrossRef]

24. Strbac-Hadzibegovic, N.; Strbac-Savic, S.; Kostic, M. A New Procedure for Determining the Road Surface Reduced Luminance Coefficient Table by On-site Measurements. Lighting Res. Technol. 2019, 51, 65-81. [CrossRef]

25. Laurent, M. Characterisation if Road Surfaces Using Memphis Mobile Gonioreflectometer. In Proceedings of the International CIE Symposium on Road Surface Photometric Characteristics, Torino, Italy, 9-10 July 2008; CIE: Vienna, Austria, 2008.

26. Jackett, M.J.; Frith, W.J. Measurement of the Reflection Properties of Road Surfaces to Improve the Safety and Sustainability of Road Lighting, NZ Transport Agency Research Report 383; NZ Transport Agency: Wellington, New Zeeland, 2009. 
27. Galatanu, C.D.; Canale, L. Measurement of Reflectance Properties of Asphalt Using Photographical Methods. In Proceedings of the International Conference on Environment and Electrical Engineering and 2020 IEEE Industrial and Commercial Power Systems Europe (EEEIC/I\&CPS Europe), Madrid, Spain, 9-12 June 2020; ISBN 978-1-7281-7455-6.

28. Commission Internationale de l'Éclairage (CIE). Road Surface and Lighting, CIE 66:1984; Commision Internanionale de l'Eclairage; Commission Internationale de l'Éclairage: Vienna, Austria, 1984; ISBN 978-3-901906-72-5.

29. Rusu, A.V.; Lucache, D.D.; Galatanu, C.D. Calculation of Energy Economy by Optimising Dimming Strategy. In Proceedings of the 19th International Conference on Environment and Electrical Engineering (EEEIC), Genoa, Italy, 11-14 June 2019.

30. Doulos, L.T.; Sioutis, I.; Kontaxis, P.; Zissis, G.; Faidas, K. A Decision Support System for Assessment of Street Lighting Tenders Based on Energy Performance Indicators and Environmental Criteria: Overview, Methodology and Case Study. Sustain. Cities Soc. 2019, 51, 101759. [CrossRef]

31. Carli, R.; Dotoli, M. A Dynamic Programming Approach for the Decentralized Control of Energy Retrofit in Large-Scale Street Lighting Systems. IEEE Trans. Autom. Sci. Eng. 2020, 17, 1140-1157. [CrossRef]

32. Carli, R.; Dotoli, M.; Pellegrino, R. A Decision-Making Tool for Energy Efficiency Optimization of Street Lighting. Comput. Oper. Res. 2018, 96, 222-234. [CrossRef] 